\title{
Lead Site aV6
}

National Cancer Institute

\section{Source}

National Cancer Institute. Lead Site aV6. NCI Thesaurus. Code C90403.

An aug mented unipolar lead placed at the sixth intercostal space on the midaxillary line. 